\title{
ROTULAGEM NUTRICIONAL DE ALIMENTOS E SUA RELAÇÃO COM OS DIREITOS DA PERSONALIDADE E COM OS DIREITOS FUNDAMENTAIS
}

\author{
Oscar Ivan Prux ${ }^{1}$ \\ Marina Weiss Gonçalves ${ }^{2}$
}

\section{Resumo:}

Sob o enfoque dos direitos da personalidade, o presente artigo, valendo-se do método hipotético-dedutivo, analisa aspectos relacionados à comercialização e consumo de alimentos. Aborda questões específicas quanto à rotulagem destes, considerando que o consumo inadequado (inapropriado ou excessivo, principalmente de ultraprocessados) gera graves consequências para a saúde do ser humano (um dos exemplos mencionados é a obesidade). Analisa, ainda, a atuação da ANVISA quanto às normas que definem as exigências e limites para a rotulagem nutricional, tudo com especial consideração quanto à proteção dos seres humanos, de seus direitos fundamentais e da personalidade (dentre outros, saúde e vida).

\section{Palavras-chave:}

Proteção ao consumidor; Rotulagem nutricional; Saúde; Direitos da personalidade; Direitos fundamentais.

\section{NUTRITIONAL LABELING OF FOODS AND ITS RELATION WITH PERSONALITY RIGHTS AND WITH FUNDAMENTAL RIGHTS}

\begin{abstract}
:
Under the approach of personality rights, this article, using the hypothetical deductivemethod, analyses aspects about the commercialization and consumption of food. Analyses issues about nutritional labeling, considering that inadequate consumption (excessive or inappropriate, especially the ultraprocessed) has serious consequences for human health (one of the examples mentioned is obesity). Also, ANVISA's performance is analysed, envolving the rules that define the requirements and limits for nutritional labeling, all with special consideration on fundamental and personality rights (among others, health and life).
\end{abstract}

\footnotetext{
${ }^{1}$ Pós Doutor pela FDUL - Faculdade de Direito da Universidade de Lisboa. Doutorado em Direito das Relações Sociais pela Pontifícia Universidade Católica de São Paulo (2001). Mestrado em Direito das Relações Sociais pela Universidade Estadual de Londrina (1995). Com licenciatura em pedagogia (2017) pela FACIBRA. Graduação em Direito pela Universidade Estadual de Londrina (1976). Graduado em Ciências Econômicas pela Fundação Faculdade Estadual de Ciências Econômicas de Apucarana (1988). Especialização em Teoria Econômica. Membro e Titular Fundador do Centro de Letras Artes e Ciências do Vale do Ivaí. Atualmente é professor do curso de mestrado em Ciências Jurídicas da UniCesumar. Foi professor convidado na Escola da Magistratura do Paraná - EMAP. Tem experiência na área de Direito, atuando principalmente nos seguintes temas: direito do consumidor; direito da concorrência, direito civil, direito empresarial e direitos da personalidade. Endereço postal: Rua Oswaldo Cruz, n 763 , Centro, Apucarana/PR, CEP 86.800-720. E-mail: prux@uol.com.br

${ }^{2}$ Mestranda em Ciências Jurídicas pelo UniCesumar. Pós-Graduanda em Direito do Consumidor pelo IBMEC/SP. Especialista em Direito Civil pela Pontifícia Universidade Católica do Paraná (2021). Graduada em Direito pela Pontifícia Universidade Católica do Paraná (2018). Endereço postal: Rua Zeferino Sanches Parra, ${ }^{\circ}$ 300, Jardim Itália, Marialva/PR, CEP 86.990-000. E-mail: marinaweissgo@gmail.com
} 
Keywords: Consumer's protection; Nutritional labeling; Health; Personality rights; Fundamental rights.

\section{INTRODUÇÃO}

Vivemos em uma sociedade de consumo, em que o destinatário final dos produtos e serviços, denominado consumidor, conta com grande variedade e quantidade de produtos à sua disposição, inclusive na seara relacionada a alimentação. Ao longo principalmente do século XX e até nossos dias, as empresas fornecedoras passaram a ocupar o espaço de valorização da diversificação e fizeram surgir, em grande escala, produtos ditos saudáveis e outros que, devido às suas características nutricionais, não são os mais indicados para uma boa alimentação, tais como os alimentos ultraprocessados. ${ }^{3}$

Vale observar que na última década a grande mídia divulgou imensa quantidade de matérias sobre aquisição e consumo de alimentos saudáveis, que representam qualidade de vida e longevidade. Ocorre que, devido ao aumento da demanda, houve uma majoração nos preços desses produtos, provocando dificuldades de acesso para parcelas significativas da população cujo poder aquisitivo é bastante limitado. De outro lado, a indústria que produz alimentos ultraprocessados se esmerou em marketing e, aproveitando do ganho de escala, conseguiu baratear esses produtos e, assim, torná-los mais acessíveis aos mais pobres. Entretanto, o inadequado consumo desse tipo de alimento implica em riscos elevados à saúde das pessoas consumidoras (sua integridade físico-psíquica), na medida em que podem causar problemas como a obesidade (verdadeira epidemia que já atinge até os mais pobres), que desencadeia uma série de outras doenças, como hipertensão, diabetes e, inclusive, diversos tipos de câncer.

Note-se que essa realidade se relaciona com deveres e responsabilidades de parte das empresas enquanto fornecedoras, não só de não colocarem no mercado produtos que possam afetar gravosamente a saúde e segurança do consumidor (art. $8^{\circ}$ do Código de Proteção e Defesa do Consumidor), mas, também, de fornecerem informação e mesmo educação sobre o consumo de seus produtos (art. $6^{\circ}$, II e II, CDC). Em paralelo, nos termos do art. $4^{\mathrm{o}}$, I e II, $\mathrm{CDC}$, reconhecendo a vulnerabilidade do consumidor, ao Estado cabe atuar nesse cenário. E

\footnotetext{
${ }^{3}$ Alimentos ultraprocessados, segundo a Associação Brasileira para o Estudo da Obesidade e da Síndrome Metabólica, são definidos como os produzidos com "adição de muitos ingredientes como sal, açúcar, óleos, gorduras, proteínas de soja, do leite, extratos de carne, além de substâncias sintetizadas em laboratório a partir de alimentos e de outras formas orgânicas como petróleo e carvão" (BRESSAN, 2018).
} 
papel especial está reservado para a regulação através da ANVISA, autarquia sob regime especial vinculada ao Ministério da Saúde, no que tange à segurança e qualidade dos produtos colocados no mercado de consumo.

É nesse contexto que em outubro de 2020, a Agência Nacional de Vigilância Sanitária publicou no Diário Oficial da União a Resolução da Diretoria Colegiada - RDC no 429, que instituiu normas sobre rotulagem nutricional de alimentos. Observando a natureza constitucional do Código de Defesa do Consumidor que, reitera-se, surgiu em razão da necessidade de consideração do princípio do reconhecimento da vulnerabilidade do consumidor e partindo de pesquisas bibliográficas, busca-se descortinar e analisar no presente artigo aspectos dessa conjuntura, incluindo as questões relacionadas à recente resolução, destacando- se, principalmente, a imposição de rotulagem nutricional frontal. E, sob o enfoque dos direitos da personalidade, à luz da teoria da qualidade, das normas da regulação e dos preceitos do CDC, busca-se, sob esse viés, abordar as situações fáticas envolvidas e as formas de assegurar esses direitos, tudo considerando um mercado de consumo em que o risco é inerente e que carece de normas que efetivamente possam proteger os consumidores quando do consumo de alimentos, incentivando o fornecimento e acesso aos alimentos saudáveis e limitando ou eliminando os produtos que contêm basicamente nutrientes críticos e afetam a saúde das pessoas.

\section{DA RAIZ CONSTITUCIONAL DO CÓDIGO DE DEFESA DO CONSUMIDOR E DA VULNERABILIDADE DO CONSUMIDOR}

A legislação brasileira de proteção ao consumidor é feita por um sistema em que se destaca a Lei $\mathrm{n}^{\circ}$ 8.078, de 11 de setembro de 1990, um código que possui raiz constitucional, pois a Constituição Federal de 1988 determinou expressamente ao Estado a promoção da defesa do consumidor, conforme preceitua o seu artigo $5^{\circ}$, XXXII. Trata-se, portanto, de direito fundamental, ${ }^{4}$ que inclusive consta do elenco de princípios dispostos para a ordem econômica, consoante artigo 170, V da Carta Magna (MIRAGEM, 2019, p. 55-56).

A defesa do consumidor é, nas palavras de Sérgio Cavalieri Filho, dever do Estado e garantia fundamental das pessoas, sendo que o CDC é um microssistema legislativo que

\footnotetext{
${ }^{4}$ Observe-se que o direito do consumidor é o direito mais próximo dos direitos humanos, pois infere para a proteção à saúde e segurança das pessoas.
} 
contém normas de ordem pública e de interesse social, suficiente em si mesmo do ponto de vista hermenêutico. Ainda, o autor afirma que se está diante de lei principiológica, posto que cria normas de sobredireito, e de lei de caráter especial, na medida em que visa proteger uma categoria de sujeito e não regrar uma matéria (CAVALIERI FILHO, 2014, p. 11-23).

Sobre o caráter principiológico do CDC, cumpre destacar que o seu escopo é concretizar, em norma infraconstitucional, os princípios e garantias constitucionais, tornando explícitos, nas relações de consumo, os comandos constantes da Lei Maior (RIZZATTO NUNES, 2017, p. 112-113).

A Constituição de 1988 buscou, após as profundas transformações sociais ocorridas no Século XX, aproximar as esferas pública e privada, abandonando o conceito liberal clássico de Constituição, que visava a preservação da liberdade individual do homem em relação ao Estado, e tomando como base o princípio da dignidade da pessoa humana (MIRAGEM, 2019, p. 56-57). O capitalismo brasileiro, seguindo o mandamento constitucional do artigo 170, funda-se na livre iniciativa com responsabilidade social, não sendo ampla, total e irrestrita (RIZZATTO NUNES, 2017, p. 44-45), ou seja, a ordem econômica deve garantir existência digna, conforme os ditames da justiça social (MORAES, 2014, p. 839).

E esse cenário em muito se relaciona com a qualidade da alimentação, preocupação que deve estar presente nas políticas do Estado, na atuação das empresas fornecedoras e nas escolhas dos consumidores, no sentido de privilegiar alimentos saudáveis. Reitera-se que o Código de Defesa do Consumidor em si, elenca como um dos princípios da Política Nacional das Relações de Consumo o reconhecimento da vulnerabilidade do consumidor no mercado de consumo. A vulnerabilidade é, portanto, presunção iuris et iure e ponto de partida de sua aplicação, sendo atributo que deve ser conferido para alcance da tutela dos direitos pelos consumidores (CAVALIERI FILHO, 2014, p. 49).

Entre as espécies de vulnerabilidade, e frente à brevidade do artigo, destacam-se: a vulnerabilidade técnica, que consiste na ausência, por parte do consumidor, de conhecimentos específicos sobre o processo produtivo e sobre os atributos específicos de produtos e serviços (CAVALIERI FILHO, 2014, p. 51) e a presunção de que o fornecedor detém expertise e conhecimento exato das características essenciais do produto/serviço que fornece (MIRAGEM, 2019, p. 199), e a vulnerabilidade fática que decorre da maior capacidade econômica e social dos agentes econômicos e das situações específicas relativas a alguns 
consumidores como, por exemplo, as crianças, os idosos e os analfabetos (MIRAGEM, 2019, p. 200).

A esse limitado apanhado (pois existem outras vulnerabilidades que podem ser reconhecidas) pode-se acrescentar a vulnerabilidade política e legislativa, que se caracteriza pela ausência ou debilidade do poder do consumidor frente ao lobby dos fornecedores junto ao Poder Legislativo, principalmente parlamentares, e demais autoridades públicas (MIRAGEM, 2019, p. 200).

O CDC trata, portanto, de maneira desigual os consumidores, conferindo-lhes prerrogativas legais para que se alcance a igualdade real imposta pela Constituição Federal, posto que não detêm os mecanismos de controle do processo produtivo (CAVALIERI FILHO, 2014, p. 49-50), ficando expostos aos riscos de serem atingidos em suas mais diversas esferas.

Ressalte-se que o princípio da igualdade da Constituição Federal permite tratamento desigual entre desiguais, na medida de sua desigualdade, desde que com o objetivo de assegurar a verdadeira Justiça (no sentido amplo de acesso à uma ordem jurídica justa). Ou seja, o elemento discriminador deve servir para se alcançar a finalidade acolhida pelo direito (MORAES, 2014, p. 35): no caso, tutelar a parte mais fraca em uma relação de consumo.

Assim, tendendo, portanto, a um mandamento constitucional, o Código de Defesa do Consumidor foi criado e a tutela do consumidor constitui-se em um princípio constitucional que se impõe perante o ordenamento jurídico, servindo como verdadeira diretriz de interpretação. Sempre que haja relação de consumo, aplica-se o CDC para tutela do sujeito que a lei entende como parte mais fraca da relação e a quem concede prerrogativas legais que facilitam a tutela de seu direito, assegurando o princípio da igualdade previsto pela Constituição Federal.

No caso da qualidade da alimentação, a aplicação do CDC é imprescindível, inclusive para nortear a regulação. Como se sabe, o mercado de alimentos envolve aspectos multifacetados que incluem a fórmula de composição, a fabricação, a apresentação quando da oferta para o consumidor (incluindo a publicidade, a embalagem, a rotulagem, etc.), bem como, o cumprimento por parte do fornecedor do dever de informar sobre o produto, inclusive com educação para o consumo adequado (principalmente em se tratando de alimentos ultraprocessados). 
Nesse amplo cenário, então, há questões centrais que envolvem o processo de criação, composição, fabricação e consumo, mas, em específico, a rotulagem tem importância decisiva e sua adequação ocupa lugar destacado no tocante ao desiderato de proteção do consumidor de alimentos.

\section{ASPECTOS SOBRE ROTULAGEM NUTRICIONAL DE ALIMENTOS NO BRASIL}

Uma das primeiras distinções importantes para serem feitas, reside na diferença entre embalagem e rotulagem, muito embora a segunda possa estar inserida na primeira.

O que serve de invólucro e proteção para a conservação do produto é a embalagem, que no caso dos alimentos industrializados, a par desse tipo de utilidade, no mercado de consumo atual, também tem sido frequentemente aproveitada como peça de marketing, seja na forma, seja nos desenhos, cores e outros detalhes que apresenta, todos cuidadosamente planejados, muitas vezes até com base em conhecimentos advindos da neurociência, visando atrair os consumidores para a aquisição.

Já a rotulagem apresenta as informações determinadas pela legislação para que o direito à informação (art. $6^{\circ}, \mathrm{III}, \mathrm{CDC}$ ) seja respeitado em prol da proteção ao consumidor. É nela que devem constar as fórmulas, a composição do produto e os alertas que sejam impositivos conforme a legislação, ou seja, a informação em sentido amplo que, em regra (pois pode haver necessidade de apresentar outros aspectos mais) deve atender à condição de informação-conteúdo e informação-advertência. ${ }^{5}$ Inclusive, é muito útil e muitas vezes

\footnotetext{
${ }^{5}$ Veja-se o exemplo:

[...] Com base no CDC (Lei n. 8.078/1990) e na Lei do Glúten (Lei n. 10.674/2003), o acórdão embargado deu provimento a embargos de divergência para que prevaleça a tese segundo a qual a expressão "contém glúten" é, por si só, insuficiente para informar os consumidores sobre o prejuízo que o alimento com glúten acarreta ao bem-estar dos doentes celíacos, tornando-se necessária que a informação-conteúdo seja integrada pela informação-advertência, correta clara, precisa, ostensiva e em vernáculo "CONTÉM GLÚTEN: O GLÚTEN É PREJUDICIAL À SAÚDE DOS DOENTES CELÍACOS". BRASIL. Superior Tribunal de Justiça. Embargos de declaração nos embargos de divergência em recurso especial 1.515.895/MS. PROCESSO CIVIL. PROCESSO COLETIVO. DIREITO DO CONSUMIDOR. EMBARGOS DE DECLARAÇÃO. INFORMAÇÃO-ADVERTÊNCIA NA ROTULAGEM DOS ALIMENTOS QUE CONTÉM GLÚTEN. AUSÊNCIA DE OMISSÃO, CONTRADIÇÃO, OBSCURIDADE OU ERRO MATERIAL. INTUITO DE DEBATE DE DISPOSITIVOS CONSTITUCIONAIS. INEXISTÊNCIA DE VÍCIOS NO JULGADO. Embargante: Panificadora Pão Bento LTDA - Microempresa. Embargado: Associação dos Aposentados, Pensionistas e Idosos de Campo Grande e do Estado do Mato Grosso do Sul. Relator: Ministro Humberto Martins, 20 de novembro de 2017. Disponível em:
} 
indispensável que também contenha informação-aconselhamento, pois fundamental para o exercício do direito de escolha e, também, porque cria a possibilidade para as pessoas de optarem por um consumo que seja adequado e saudável dos produtos alimentícios.

Nesse contexto, emergem deveres para os fornecedores e, em se tratando de rotulagem, retoma-se a referência à Resolução de Diretoria Colegiada ${ }^{\circ}$ 429/2020, editada pela ANVISA, a qual, em suas disposições sobre a rotulagem nutricional de alimentos, introduziu inovações importantes. Nessa norma, que pode ser tida como recente, o artigo $1^{\circ}$ prescreve a imposição da declaração de tabela nutricional como obrigatória nos rótulos dos alimentos (artigo $2^{\circ}, \mathrm{RDC}^{\circ}$ 429/2020) explicitando aspectos como: quais os nutrientes que nela devem ser colocados (artigo $5^{\circ}, \mathrm{RDC}^{\circ}$ 429/2020); a padronização de medidas, sendo 100 gramas para sólidos e semissólidos e 100 mililitros para líquidos (artigo 8 RDC $\mathrm{n}^{\circ}$ 429/2020); a imposição de padronização na formatação da tabela, cujas letras devem ser pretas em fundo branco, observando espaçamento entre linhas, fonte tamanho 8 (oito) na formatação padrão e 6 (seis) na reduzida (artigo 16, RDC n 429/2020); a rotulagem nutricional frontal em alimentos que extrapolem os limites de açúcares adicionados, gorduras saturadas e sódio impostos pelo Anexo XV da Instrução Normativa - IN n 75 de 2020 (artigo 18, RDC n429/2020).

Todas essas prescrições são importantes, mas cabe centrar a abordagem naquela que provocou maior polêmica, no caso a relacionada com a rotulagem nutricional frontal.

Principia-se por mencionar que em 2017, o Instituto Brasileiro de Defesa do Consumidor, inspirado no modelo de octógonos adotado pelo Chile desde 2016, juntamente com especialistas em design da informação da Universidade Federal do Paraná, propôs o modelo de alerta de triângulos para a rotulagem nutricional frontal, afirmando ser mais eficaz para informar o consumidor na hora da compra (MILESKI, 2020).

Inicialmente, em 2018, em seu Relatório Preliminar de Análise de Impacto Regulatório sobre Rotulagem Nutricional, a ANVISA também demonstrou estar inclinada à adoção do modelo de alerta, ao invés do modelo de semáforo nutricional sugerido pela indústria de alimentos, afirmando que:

[...] o conjunto das evidências revisadas permite concluir que os modelos semiinterpretativos de alertas possuem melhor desempenho em relação ao

https://processo.stj.jus.br/processo/revista/documento/mediado/?componente=ITA\&sequenc ial $=1656859 \&$ num_registro $=201500354240 \&$ data $=20171215 \&$ peticao_numero $=2017005166$ 85\&formato=PDF. Acesso em 12 abr. 2021. 
semáforo nutricional na: (a) captura da atenção; (b) compreensão da informação sobre alto conteúdo de nutrientes negativos; (c) redução da percepção de saudabilidade de produtos com alto teor de nutrientes negativos; (d) redução da percepção de frequência de consumo de alimentos com alto teor de nutrientes negativos; (e) intenção de compras [...] (RELATÓRIO PRELIMINAR DE ANÁLISE DE IMPACTO REGULATÓRIO SOBRE ROTULAGEM NUTRICIONAL, 2018, p. 16)

Entretanto, o modelo aprovado em 2020 foi o de design de lupa, cuja eficácia não se revela negativa, mas reduzida quando comparado com outros modelos, em especial no tocante à legibilidade, clareza e simplicidade gráficas comprometidas. Ainda, o IDEC critica a decisão da ANVISA de deixar de fora da rotulagem nutricional frontal os alertas para adoçantes e a falta de limite mais rigoroso do perfil de nutrientes selecionados (açúcares, gorduras saturadas e sódio) (IDEC, 2020).

A adoção dessa opção de modelo de rotulagem aconteceu em meio a denúncias de que a indústria de alimentos ultraprocessados interferiu no processo de definição das regras sobre a rotulagem nutricional, bem como que o modelo de lupa foi adotado mediante influência da Associação Brasileira da Indústria de Alimentos. E mais, conforme afirmação do IDEC, durante o processo de discussão das normas teria sido conferido às empresas privadas um tratamento privilegiado, já que teriam tido mais acesso às diretorias da ANVISA do que as organizações da sociedade civil (IDEC, 2021).

É indubitável - sem que por si só seja recriminável - que a iniciativa privada busca alcançar e proteger seus interesses. Assim, diante da inexistência de um marco legal de regulação do lobby no Brasil, o que pode ser verificado é uma intensa atuação das empresas em temas que lhes interessam e que se relacionam com a autonomia da ANVISA em termos de regulação. Há incisiva busca por parte dessas empresas de apoio junto a órgãos do Poder Executivo e do Congresso Nacional, com articulação de campanhas publicitárias que, em matérias veiculadas na mídia, utilizaram como argumento principal a acusação de que as normas que imporiam uma rotulagem mais assertiva nas informações seriam economicamente desastrosas (DE AZEVEDO, 2019, p. 60-62).

Tem-se aí alegação de aspectos fáticos que não condizem com a verdade, ou com a melhor proteção da saúde e da vida (com qualidade) para o consumidor, o que faz parte dos direitos humanos, fundamentais e da personalidade. E nesse ponto, especial referência deve 
ser feita, também, para as disposições da já citada Lei no 8.078/90, espécie de "nau capitânia" do sistema de proteção ao consumidor. ${ }^{6}$

Sobre o direito à vida, saúde e segurança, defende-se que são inalienáveis e indissociáveis do princípio da dignidade da pessoa humana e visam proteger a incolumidade físico-psíquica dos consumidores. Ressalte-se, assim, a importância da concretização dos princípios da segurança (os produtos devem ser adequados aos fins a que se destinam e devem ser seguros) e da prevenção (o fornecedor colocará no mercado apenas produtos e serviços que não acarretem riscos ao consumidor) (CAVALIERI FILHO, 2014, p. 100), sendo que tais princípios podem ou não se tornar explícitos, também, pela forma e conteúdo constante na rotulagem.

Quanto ao direito à educação para o consumo, na prática, este resta inviável quando se leva em consideração o padrão de rotulagem adotado, um dos elementos fundamentais para esclarecimento da pessoa a respeito do produto alimentício que pretende adquirir e consumir. Relembre-se que, segundo Sérgio Cavalieri Filho (2014, p. 101), a educação para o consumo abrange o aspecto formal (através de políticas que implementem direito do consumidor nos currículos escolares) e o informal (através de mídias de comunicação social e institucional).

Para isso, sublinhe-se, é preciso haver rotulagem que, da melhor forma, forneça as informações necessárias ao consumidor, afinal, as informações devem ser suficientes para exercer o consentimento esclarecido (CAVALIERI FILHO, 2014, p. 103), sendo que o conteúdo daquelas que forem substanciais deve ser estabelecido em cada caso concreto, considerando as especificidades dos produtos alimentícios (principalmente os ultraprocessados), impondo-se que sejam transmitidas de forma clara, adequada e que permita verdadeira compreensão por parte do consumidor (MIRAGEM, 2019, p. 289). Outro detalhe: importante referir que na rotulagem devem constar os alertas para componentes alergênicos (como, por exemplo, o glúten), de modo que a eficácia de fazer chegar ao consumidor os alertas revela-se essencial para preservar a saúde da pessoa consumidora.

E, nesse ponto, a rotulagem no já mencionado modelo utilizado pelo Chile apresenta conteúdo mais incisivo e esclarecedor. De outro modo, no modelo brasileiro preconizado pela ANVISA, o consumidor, diante da redução de eficácia do padrão de alerta nos alimentos que

\footnotetext{
${ }^{6}$ Que textualmente elenca como direitos básicos dos consumidores a proteção à vida, à saúde, à segurança (artigo $6^{\circ}, \mathrm{I}, \mathrm{CDC}$ ), à educação e divulgação sobre consumo adequado dos produtos e serviços (artigo $6^{\circ}$, II, CDC) e à informação adequada e clara sobre os diferentes produtos e serviços, com especificação correta de quantidade, características, composição, qualidade e riscos que apresentem (artigo $6^{\circ}, \mathrm{III}, \mathrm{CDC}$ ).
} 
contêm nutrientes críticos e do menor rigor de limite dos nutrientes selecionados, tem seu direito à informação violado e, em consequência, seu direito à vida (com qualidade), à saúde e à segurança, já que diversos problemas de saúde acabam desencadeados pelo consumo de alimentos ultraprocessados.

Em que pese a RDC n 429/2020, no que diz respeito à rotulagem nutricional, tenha sido apresentada como avanço quando comparada com a legislação anterior, é de se crer que se perdeu uma grande oportunidade para um aperfeiçoamento maior. Considerada a teoria da qualidade, que prega a proteção e atendimento para as legítimas expectativas do consumidor desses alimentos, é de se questionar se o modelo preconizado pelas associações civis não deveria ter sido o escolhido para adoção no Brasil, pois, com base em estudos referidos por elas (MILESKI, 2020), são mais aptos a produzir resultados mais benéficos. O consumidor é reconhecidamente vulnerável (por vezes, dotado de vulnerabilidade agravada, ou seja, hipossuficiente ou hipervulnerável) por não deter conhecimentos técnicos e nem domínio sobre os processos produtivos, necessitando, portanto, de especial proteção, a mais acurada e elevada possível, principalmente porque se está a tratar de produtos alimentícios.

O consumidor não pode ficar exposto às práticas do mercado de consumo que possam impactar de forma negativa seus direitos, nem mesmo às que os reduzam. $\mathrm{O}$ ideal é que não fossem fabricados e comercializados produtos alimentícios não saudáveis, mas enquanto essa utopia não tem viabilidade, focando na realidade, cabe manifestar que a flexibilização do rigor quanto à informação sobre os nutrientes críticos dos alimentos e a singela imposição do design de lupa, que possui eficácia reduzida quando comparada com os demais modelos de alerta, revelam-se um equívoco danoso. Assim, o direito à informação restou limitado/restringido, bem como a proteção do direito à segurança alimentar (no sentido da preservação da saúde e da vida em face de alimentos não saudáveis), já que a rotulagem imposta não alerta suficientemente para a prevenção quanto aos diversos riscos decorrentes do consumo de alimentos ultraprocessados, consoante se demonstrará no tópico a seguir.

\section{DADOS EMPÍRICOS SOBRE OS IMPACTOS DA MÁ-ALIMENTAÇÃO NA SAÚDE DO BRASILEIRO}

É de conhecimento geral que os alimentos ultraprocessados, devido aos sabores artificiais adicionados, são atrativos e que seu preço pode ser mais interessante em 
comparação ao dos alimentos saudáveis, inclusive atraindo aos mais pobres. Entretanto, o resultado do maior consumo desses alimentos tem consequências que chamam a atenção quando se pensa no princípio da precaução.

O Guia Alimentar para a População Brasileira, emitido pelo Ministério da Saúde em 2014, defende que o consumo de alimentos ultraprocessados deve ser evitado, pois estes envolvem "diversas etapas e técnicas de processamento e muitos ingredientes, incluindo sal, açúcar, óleos e gorduras e substâncias de uso exclusivamente industrial" (GUIA ALIMENTAR PARA A POPULAÇÃO BRASILEIRA, 2014, p. 39). Em suma, os referidos alimentos contêm composição nutricional desbalanceada, já que sendo ricos em açúcares, gorduras e sódio, em contraposição são pobres em fibras, vitaminas, minerais e outras substâncias com atividade biológica, contexto em que acaba favorecido o consumo excessivo de calorias, podendo provocar doenças no coração, diabetes, diversos tipos de câncer e deficiências nutricionais (GUIA ALIMENTAR PARA A POPULAÇÃO BRASILEIRA, 2014, p. 42-43).

Segundo dados da Pesquisa Nacional de Saúde, realizada pelo Instituto Brasileiro de Geografia e Estatística em 2019, no período de 2002 a 2003 o percentual da população adulta brasileira com excesso de peso era 43,3\%. Em 2019, ou seja, apenas seis anos depois, o percentual já tinha saltado para 61,7\%. Entre adolescentes com idades entre 15 (quinze) e 17 (dezessete) anos, um em cada cinco estava com excesso de peso. Na faixa etária de pessoas de 18 (dezoito) a 24 (vinte e quatro) anos, um terço estava com excesso de peso, enquanto entre as pessoas de 40 (quarenta) a 59 (cinquenta e nove) anos, o percentual era de 70,3\% (IBGE, 2020), o que demonstra que o excesso de peso decorrente da incorreta alimentação se faz ainda mais gravoso com o aumento da idade.

Laborando com dados sobre a obesidade, o IBGE aponta que entre as pessoas com 18 (dezoito) anos ou mais, 25,9\% estavam obesas, totalizando 41 milhões e duzentas mil pessoas. Já entre as pessoas com 20 (vinte) anos ou mais, entre 2002 e 2003 a obesidade alcançava 12,2\% da população e em 2019 esse percentual saltou para 26,8\% (IBGE, 2020). Há vários fatores que influenciam essa realidade, mas esses dados estão intrinsecamente ligados à qualidade da alimentação, ou seja, ao crescimento do volume de consumo dos já referidos alimentos industrializados.

Embora não se desconheça poder haver em parte das pessoas alguma predisposição genética para a obesidade, a Organização Mundial da Saúde cita como um importante fator 
para seu desenvolvimento exatamente o ambiente obesogênico em que vivemos, no qual diversas e dominantes são as opções de alimentos baratos cuja densidade energética é alta e há redução da realização de atividades físicas, causando excesso de peso (OMS).

O Hospital Israelita Albert Einstein também afirma que a principal causa da obesidade é a alimentação inadequada ou excessiva. A obesidade ocorre quando há um desequilíbrio entre a quantidade de calorias ingeridas e a quantidade de energia gasta, ou seja, o sedentarismo também está associado às causas da obesidade. O hospital destaca, entretanto, que não podem ser afastados os fatores genéticos, a existência de metabolismos lentos e a ocorrência oscilações hormonais (ROSENBAUM). Mas os alimentos inadequados fornecem, por assim dizer, "a matéria-prima" para que os demais fatores atuem ou se agravem.

Estudos recentes do Instituto Nacional de Câncer demonstram que quanto aos gastos do Sistema Único de Saúde em 2018, dos R \$1,7 bilhão com tratamento oncológico, R \$700 milhões foram em tratamentos contra cânceres associados ao excesso de peso, especialmente tumores malignos de mama, intestino grosso (colorretal) e endométrio (INCA, 2021). Em sua conclusão, a pesquisa do INCA afirma que os gastos com cânceres associados ao excesso de peso, como de rim, próstata, fígado, pâncreas, ovário, esôfago, estômago e vesícula, representam um fardo econômico substancial para o sistema público de saúde (DA SILVA, 2021).

A obesidade é elencada como fator de risco para o desenvolvimento de hipertensão, cardiopatias e diabetes (REZENDE; GARDENGHI, 2021). Dados demonstram que em 2018, $16 \%$ do total de internações hospitalares no SUS, equivalente a 1.829 .779 (um milhão, oitocentos e vinte e nove mil, setecentas e setenta e nove) internações, estavam associadas à hipertensão, diabetes e obesidade, totalizando $\mathrm{R} \$ 3,84$ bilhões de custo aos cofres públicos. Quanto aos custos ambulatoriais, no mesmo ano, referidas doenças totalizaram um custo de R \$166 milhões, enquanto os gastos com o Programa Farmácia Popular com medicamentos para hipertensão, diabetes e asma alcançaram um total de R \$2,31 bilhões (NILSON, 2020).

Conforme demonstrado, a obesidade é um problema de saúde pública, que pode levar ao desenvolvimento de diversas outras doenças, como câncer, cardiopatias, hipertensão e diabetes. Apesar de estar associada a fatores genéticos (posto que algumas pessoas possuem pré-disposição para desenvolvê-la), a metabolismos mais lentos e oscilações hormonais, a máalimentação e o sedentarismo estão entre as causas principais de seu desenvolvimento. 
No presente artigo, não se busca excluir as orientações para as pessoas praticarem hábitos saudáveis, inclusive como forma de gastar calorias e melhorar a saúde física e mental (já que a Pesquisa Nacional de Saúde de 2019 apontou que 40,3\% da população adulta brasileira é insuficientemente ativa - não pratica atividade física ou pratica por menos de cento e cinquenta minutos por semana) (IBGE, 2019, p. 46), nem mesmo ignorar questões genéticas associadas à obesidade. $\mathrm{O}$ que se questiona, porém, são os novos padrões de alimentação impostos pela globalização, que tendem a estimular o consumo de alimentos ultraprocessados, constituídos de nutrientes críticos, como sódio, açúcares e gorduras, que prejudicam a saúde do consumidor.

Todo esse contexto, reitera-se, integra um problema de saúde pública, posto o notório prejuízo para a qualidade de vida da população e por representar, consoante demonstrado, um custo substancial aos cofres públicos, principalmente devido ao dever estatal de fornecer tratamentos, inclusive oncológicos, internações e medicações. Portanto, está-se diante de um problema que atinge a todos, pois o dinheiro dos contribuintes vai para o Poder Público que, obedecendo ao comando do artigo 196 da Constituição Federal, o despende para atender essas situações, afinal, conforme texto expresso, a saúde é direito de todos e dever do Estado. E, naquilo que é o mais importante, a saúde, além de ser direito fundamental, está intimamente relacionada aos direitos da personalidade, direitos esses intrínsecos à qualidade de pessoa e necessários para que cada um possa exercer sua individualidade.

\section{RELAÇÃO ENTRE ROTULAGEM NUTRICIONAL, DIREITOS DA PERSONALIDADE, DIREITOS FUNDAMENTAIS E DEMOCRACIA}

Ao Estado constitucionalmente incumbe atender à saúde, bem como o desenvolvimento de políticas sociais e econômicas que visem à redução do risco de doenças e de outros agravos em todas as circunstâncias que possam envolver esse bem da vida. E o Código Civil, no mesmo sentido, elenca a vida e a integridade física como direitos da personalidade.

Existe técnica diferença entre direitos fundamentais e direitos da personalidade, mas também muitas similaridades e coincidências. Os direitos fundamentais, encontram-se previstos na Constituição Federal, que impõe sua observância ao Estado, como forma de limitação de seu poder; os direitos da personalidade, por sua vez, estão inscritos no Código 
Civil e, em regra, são direcionados basicamente para observância nas relações entre particulares (NAVES; DE SÁ, 2017, p. 11-17).

Os direitos da personalidade são definidos por Carlos Alberto Bittar (2014, p. 43-44) como aqueles ínsitos à pessoa, à sua estruturação física, mental e moral, intransmissíveis e irrenunciáveis. São direitos inatos, que transcendem o ordenamento jurídico e hoje são entendidos como direitos que são intangíveis, tanto pelo Estado como pelos particulares (BITTAR, 2014, p. 43-44).

Por sua vez, os direitos fundamentais, em seu papel de limitar as ingerências indevidas do Estado na esfera do indivíduo, envolvem uma prestação negativa, mas, também, impõem uma prestação positiva, pois determinam que se deve buscar assegurar a prestação de serviços essenciais à existência e ao desenvolvimento da pessoa (SLAIBI FILHO, 2009, p. 297).

Sinalizadas as diferenciações e coincidências, possível concluir que tênue é a linha que separa os direitos da personalidade e os direitos fundamentais, já que ambos visam tutelar os bens mais relevantes e inatos aos seres humanos. Entretanto, de fácil entendimento e visualização a relação de sua aplicação quanto à rotulagem nutricional de alimentos. O direito à saúde, consagrado pela Carta Magna, é uma das vertentes do direito à vida e à integridade física, direitos estes que podem ser considerados tanto direitos da personalidade quanto direitos fundamentais.

Ao particular cabe o respeito aos direitos da personalidade dos demais. Conclusão esta que impõe ao fornecedor de produtos alimentícios, em especial de ultraprocessados, o respeito aos direitos da personalidade do consumidor. Tanto é assim, que o Código de Defesa do Consumidor consagra a proteção à vida e à saúde como direito básico (art. 6 $6^{\circ}, \mathrm{I}, \mathrm{CDC}$ ), balizando a atuação do fornecedor.

E neste ponto cabe refletir quanto à adoção do modelo de rotulagem e questionar até que ponto os referidos direitos restam respeitados, em face da já descrita flexibilização dos limites de nutrientes críticos na composição dos alimentos, bem como, da opção por modelo cuja eficácia é reduzida diante dos demais, prejudicando o acesso à informação ao consumidor, que desconhece os riscos que os alimentos ultraprocessados podem causar à sua saúde e integridade física e, em última análise, à sua vida.

Ao Estado cabe o papel de assegurar direitos e neles se incluem a saúde das pessoas (população em geral), devendo atuar em seus Três Poderes e nas esferas Federal, Estadual e 
Municipal, pois o CDC o autoriza. De forma simplificada e aplicada ao tema, ao EstadoLegislador cabe o desenvolvimento de normas que regulem a atividade dos fornecedores no mercado de consumo, não de forma a inviabilizar as atividades econômicas, mas tutelando a parte mais fraca da relação que fica exposta às práticas do mercado. Ao Poder Executivo, a realização do interesse público através da aplicação das normas editadas e a fiscalização das determinações. Ao Estado-juiz, o exercício do controle de constitucionalidade e a efetivação dos direitos dos consumidores.

Ressalte-se, ainda, que ao Estado-juiz, ante seu caráter iluminista e sem adentrar o mérito da judicialização, cabe "empurrar" a sociedade (no sentido de fazê-la avançar, evoluir), já que "questões relevantes do ponto de vista político, social ou moral estão sendo decididas, em caráter final, pelo Poder Judiciário” (BARROSO, 2018, p. 135). Aqui caberia, após a análise do caso concreto, a punição (com vistas ao caráter pedagógico e não apenas punitivo) do fornecedor que, conhecendo os riscos a que expõe a saúde dos consumidores, opta por inserir no mercado de consumo produto que possa ser considerado defeituoso (arts. $6^{\circ}, 8^{\circ}, 9^{\circ}$, 10 e $12, \mathrm{CDC})^{7}$

Saúde é Democracia, predisse a fala de Sérgio Arouca, em 1986, durante a $8^{\text {a }}$ Conferência Nacional de Saúde (FIOCRUZ, 2017), que tem seus reflexos estendidos até os dias atuais, tal como confirmou a $16^{\mathrm{a}} \mathrm{CNS}$, que teve como tema "Saúde e Democracia." O referido médico sanitarista notabilizou-se por buscar a redemocratização da saúde e auxiliar na construção do Sistema Único de Saúde, afirmando, inclusive, em concordância com a

\footnotetext{
${ }^{7}$ O Superior Tribunal de Justiça já vem discutindo questões que envolvem a composição nutricional de alimentos, em especial as que envolvem doença celíaca, impondo ao fornecedor de produtos a obrigação de informação na embalagem do produto: "contém glúten - o glúten é prejudicial à saúde dos portadores de doença celíaca" ou "não contém glúten". BRASIL. Superior Tribunal de Justiça. Agravo interno no recurso especial 1.471.245/MS. ADMINISTRATIVO. DIREITO DO CONSUMIDOR. SAÚDE. RECURSO ESPECIAL PARCIALMENTE PROVIDO. EMBARGOS DE DIVERGÊNCIA. PRODUTOS

ALIMENTÍCIOS. AUSÊNCIA DE SIMILITUDE FÁTICA. [...] A Associação dos Aposentados, Pensionistas e Idosos de Campo Grande e do Estado de MS, ajuizou a ação civil coletiva c.c. danos morais em face de Brasil Fast Food Corporation, também qualificado(a), alegando, em síntese, que a parte ré vem descumprindo determinação legal ao omitir a informação/advertência "contém glúten" ou "não contém glúten" nos seus produtos. Aduzia que o glúten, quando ingerido por pessoa portadora da doença celíaca, provoca diversas patologias. Pedia a concessão de liminar, a fim de que a parte requerida seja obrigada a inserir em seus produtos a informação: "contém glúten

- o glúten é prejudicial à saúde dos portadores de doença celíaca" ou "não contém glúten", sob pena de multa diária. Requereu a condenação ao pagamento de danos morais coletivos, em valor a ser arbitrado pelo juízo [...] Agravante: BFFC do Brasil - Comércio e Participações LTDA. Agravado: Minsitério Público do Estado do Mato Grosso do Sul. Relator: Ministro Francisco Falcão, 04 de dezembro de 2019. Disponível em: https://processo.stj.jus.br/processo/revista/documento/mediado/?componente=ATC\&sequen cial $=104215027 \&$ num_registro=201401861324\&data=20191209\&tipo=41\&formato=PDF. Acesso em 12 abr. 2021.
} 
Organização Mundial da Saúde, que a saúde não é apenas a ausência de doença, é um bemestar social que permite que a pessoa tenha acesso a outros direitos, assegurando uma vida digna (FIOCRUZ), princípio basilar da Constituição Federal.

A Constituição, ao elencar a saúde como direito fundamental, evidencia o caráter democrático de direito da República Federativa do Brasil, em que a lei é feita pelo povo, através de seus representantes, para atender aos interesses republicanos. Tendo acesso à saúde, o indivíduo pode exercer sua cidadania, através da realização de seus direitos, participando efetivamente da construção do Estado. Ou seja, a saúde permite a efetivação da cidadania, construindo a democracia brasileira.

Então, a sinalização apontada pela estrutura estatal (indicativos e permissões) por meio do conteúdo da legislação e, principalmente, com base nas determinações expedidas pela regulação (e sua fiscalização), sempre que se relacione com aspectos como a criação, a produção e o fornecimento de alimentos industrialmente ultraprocessados, não pode estar dissociada desse contexto. E a rotulagem tem proeminência nesse processo, cabendo ao Estado, por seus poderes, escolher a melhor fórmula disposta para a proteção dos direitos dos consumidores. A omissão nesta obrigação ou sua execução deficiente, formam um "edifício" que projeta sua sombra, a responsabilidade.

\section{CONCLUSÃO}

A saúde dos consumidores é direito fundamental intimamente relacionado aos direitos da personalidade. O Código de Defesa do Consumidor, âncora do sistema de proteção aos consumidores (com raiz constitucional), baseado na presunção de vulnerabilidade do destinatário final do produto, é textual em prescrever o direito à vida, à saúde, à segurança, bem como, à informação e educação para o consumo adequado dos produtos, neste caso, dos alimentos.

O mercado de consumo coloca à disposição do consumidor diversos alimentos, entre os quais, devido ao fenômeno da globalização, destacam-se os ultraprocessados, que possuem em sua composição nutrientes críticos como açúcares, sódio e gorduras. Entretanto, é demonstrável que existe carência de informações sobre os riscos que esses nutrientes importam à saúde do consumidor, contribuindo para o desenvolvimento de doenças, a exemplo da obesidade e suas decorrências sobre outras patologias. 
Frente à vulnerabilidade técnica, fática e legislativa do consumidor, e diante de seu direito à informação, sobressai o papel destacado que ocupa a RDC n 429/2020 editada pela ANVISA. Todavia, referida resolução flexibilizou limites e desconsiderou aspectos relacionados a outros nutrientes críticos, como os adoçantes, além de adotar modelo com eficácia reduzida quando comparado com os demais. O que se verifica, então, é a redução do direito à informação, com consequente limitação do direito à vida, à saúde e à integridade física, direitos esses elencados à categoria de direitos fundamentais, com intrínseca relação com os direitos da personalidade, já que necessários para que o indivíduo possa exercer sua individualidade.

Por fim, conclui-se pela importância da inserção dos autênticos valores constitucionais, em especial o desenvolvimento da livre iniciativa que respeite a cidadania e a dignidade da pessoa, nos aspectos relacionados à rotulagem dos alimentos, como forma de construir uma sociedade melhor, que realmente ampare os consumidores e assegure seus direitos.

\section{REFERÊNCIAS}

ANVISA. Relatório preliminar de análise de impacto regulatório sobre rotulagem nutricional. Brasília, 2018. Disponível em:

https://www.gov.br/anvisa/pt-br/assuntos/regulamentacao/air/analises-de-impactoregulatorio/2019/relatorio-de-analise-de-impacto-regulatorio-sobre-rotulagemnutricional.pdf/view. Acesso em 08 abr. 2021.

ANVISA. Resolução de Diretoria Colegiada n ${ }^{\circ} 429$, de 08 de outubro de 2020. Dispõe sobre a rotulagem nutricional dos alimentos embalados. Diário Oficial da União: seção 1, Brasília, DF, edição 195, p. 106, 09 de outubro de 2020. Disponível em: https://www.in.gov.br/en/web/dou/-/resolucao-de-diretoria-colegiada-rdc-n429-de-8- de-outubro-de-2020-282070599. Acesso em 01 abr. 2021.

BARROSO, Luís Roberto. Judicialização da vida e o papel do Supremo Tribunal Federal. Belo Horizonte: Fórum, 2018.

BITTAR, Carlos A. Os Direitos da Personalidade. 8. ed. São Paulo: Saraiva, 2014.

BRASIL. Lei ${ }^{\circ}$ 8.078, de 11 de setembro de 1990. Dispõe sobre a proteção do consumidor e dá outras providências. Brasília, DF. Disponível em: http://www.planalto.gov.br/ccivil_03/leis/18078compilado.htm. Acesso em 05 abr. 2021.

BRASIL. [Consituição (1988)]. Constituição da República Federativa do Brasil de 1988. Brasília, DF: Presidência da República, [2020]. Disponível em:

http://www.planalto.gov.br/ccivil_03/constituicao/constituicao.htm. Acesso 
BRASIL. Ministério da Saúde. Guia alimentar para a população brasileira. 2. ed. Brasília, DF, 2014. Disponível em:

https://bvsms.saude.gov.br/bvs/publicacoes/guia_alimentar_populacao_brasileira_2ed.pdf. Acesso em 05 abr. 2021

BRASIL. Superior Tribunal de Justiça. Agravo interno no recurso especial 1.471.245/MS. ADMINISTRATIVO. DIREITO DO CONSUMIDOR. SAÚDE. RECURSO ESPECIAL PARCIALMENTE PROVIDO. EMBARGOS DE DIVERGÊNCIA. PRODUTOS ALIMENTÍCIOS. AUSÊNCIA DE SIMILITUDE FÁTICA. Agravante: BFFC do Brasil - Comércio e Participações LTDA. Agravado: Minsitério Público do Estado do Mato Grosso do Sul. Relator: Ministro Francisco Falcão, 04 de dezembro de 2019. Disponível em:

https://processo.stj.jus.br/processo/revista/documento/mediado/?componente=ATC\&sequen cial $=104215027 \&$ num_registro $=201401861324 \&$ data $=20191209 \&$ tipo= $=41 \&$ formato $=$ PD. Acesso em 12 abr. 2021.

BRASIL. Superior Tribunal de Justiça. Embargos de declaração nos embargos de divergência em recurso especial 1.515.895/MS. PROCESSO CIVIL. PROCESSO COLETIVO. DIREITO DO CONSUMIDOR. EMBARGOS DE DECLARAÇÃO. INFORMAÇÃO-ADVERTÊNCIA NA ROTULAGEM DOS ALIMENTOS QUE CONTÉM GLÚTEN. AUSÊNCIA DE OMISSÃO, CONTRADIÇÃO, OBSCURIDADE OU ERRO MATERIAL. INTUITO DE DEBATE DE DISPOSITIVOS CONSTITUCIONAIS. INEXISTÊNCIA DE VÍCIOS NO JULGADO. Embargante: Panificadora Pão Bento LTDA - Microempresa. Embargado: Associação dos Aposentados, Pensionistas e Idosos de Campo Grande e do Estado do Mato Grosso do Sul. Relator: Ministro Humberto Martins, 20 de novembro de 2017. Disponível em: https://processo.stj.jus.br/processo/revista/documento/mediado/?componente=ITA\&sequen cial $=1656859 \&$ \&um_registro $=201500354240 \&$ data $=20171215 \&$ peticao_numero $=2017005$ 166 85\&formato=PDF. Acesso em 12 abr. 2021.

BRESSAN, Renata. Alimentos processados e ultraprocessados. Abeso, 2018. Disponível em: https://abeso.org.br/alimentos-processados-e-ultraprocessados/. Acesso em 08 abr. 2021.

CAVALIERI FILHO, Sérgio. Programa de direito do consumidor. 4. ed. São Paulo: Atlas, 2014.

DA SILVA, Ronaldo Corrêa Ferreira; BAHIA, Luciana Ribeiro; DA ROSA, Michelle Quarti Machado; MALHÃO, Thainá Alves; MENDONÇA, Eliane de Paula; ROSA, Roger dos Santos; ARAÚJO, Denizar Vianna; MOREIRA, Luciana Grucci Maya; SCHILITHZ, Arthur Orlando Corrêa; MELO, Maria Eduarda Leão Diógenes. Custos do câncer atribuíveis ao excesso de peso corporal no sistema público de saúde brasileiro em 2018. Plos One, 2021. Disponível em: https://journals.plos.org/plosone/article?id=10.1371/journal.pone.0247983. Acesso em 09 abr. 2021. 
DE AZEVEDO, Eliane. Lobbies alimentares. Revista Ingesta, São Paulo, vol. 1, n. 1. 2019. Disponível em:

https://www.revistas.usp.br/revistaingesta/article/view/151145/151758. Acesso em 08 abr. 2021.

FIOCRUZ. Dia do sanitarista: "Saúde é bem-estar físico, mental, social e político". Disponível em: https://cee.fiocruz.br/?q=node/505. Acesso em 13 abr. 2021.

FIOCRUZ. Saúde é democracia. Disponível em: https://pensesus.fiocruz.br/sa\%C3\%BAde-\%C3\%A9democracia\#: : :text=\%22Sa\%C3\%BAde $\% 20 \% \mathrm{C} 3 \%$ A9\%20democracia\%E2\%80\%9D\%20 \%C 3\%A9\%20uma,CNS)\%2C\%20realizada\%20em\%201986. Acesso em 13 abr. 2021.

IBGE. Pesquisa Nacional de Saúde. Percepção do estado de saúde, estilos de vida, doenças crônicas e saúde bucal. 2019. Disponível em: https://biblioteca.ibge.gov.br/visualizacao/livros/liv101764.pdf. Acesso em 12 abr. 2021.

IBGE. Um em cada quatro adultos do país estava obeso em 2019; Atenção primária foi bem avaliada. Agência IBGE Notícias, 2020. Disponível em: https://agenciadenoticias.ibge.gov.br/agencia- noticias/2012-agencia-denoticias/noticias/29204-um-em-cada-quatro-adultos-do-pais-estava- obeso-em2019\#: :text=A\%20preval\%C3\%AAncia\%20foi\% 20maior\%20entre,excesso\%20de\%20pS so $\% 20 \mathrm{em} \% 202019$. Acesso em 08 abr. 2021.

IDEC. IDEC reprova decisão sobre rotulagem nutricional de alimentos. IDEC, 2020. Disponível em: https://idec.org.br/noticia/idec-reprova-decisao-sobre-rotulagemnutricional-de-alimentos. Acesso em 08 abr. 2021.

IDEC. Indústria de alimentos interfere em modelo de rotulagem para garantir lucro e prejudica saúde do consumidor. IDEC, 2021. Disponível em: https://idec.org.br/noticia/industria-de-alimentos-interfere-na-definicao-de-modelo-derotulagem-e-nao-prioriza. Acesso em 08 abr. 2021.

INCA. Gastos do SUS com cânceres associados ao excesso de peso somam 41,1\% do investimento em tratamento oncológico. INCA, 2021. Disponível em:

https://www.inca.gov.br/noticias/gastos-do-sus-com-canceres-associados-ao-excesso-depeso-somam-411-do-investimento-e. Acesso em 09 abr. 2021.

MILESKI, Maria Fernanda. Nova rotulagem aprovada pela ANVISA é avaliada por pesquisadores de design da UFPR. UFPR, 2020. Disponível em:

https://www.ufpr.br/portalufpr/noticias/nova-rotulagem- aprovada-pela-anvisa-e-avaliadapor-pesquisadores-de-design-da-ufpr/. Acesso em 13 abr. 2021.

MIRAGEM, Bruno. Curso de direito do consumidor. 8. ed. São Paulo: Revista dos Tribunais, 2019.

MORAES, Alexandre de. Direito constitucional. 30. ed. São Paulo: Atlas, 2014. 
NAVES, Bruno Torquato de Oliveira; DE SÁ, Maria de Fátima Freire. Direitos da personalidade. Belo Horizonte: Arraes, 2017.

NILSON, Eduardo Augusto Fernandes; ANDRADE, Refaella da Costa Santin; DE BRITO, Daniela Aquino; DE OLIVEIRA, Michele Lessa. Custos atribuíveis a obesidade, hipertensão e diabetes no Sistema Único de Saúde. Revista Panamericana de Salud Pública, 2020. Disponível em: https://scielosp.org/article/rpsp/2020.v44/e32/\#. Acesso em 09 abr. 2021.

OMS. Obesity is a disease. Disponível em:

https://www.worldobesityday.org/assets/downloads/Obesity_Is_a_Disease.pdf. Acesso em 09 abr. 2021.

REZENDE, Roberdana. GARDENGHI, Guilliano. Obesidade como fator de risco para doenças cardiovasculares. Disponível em: https://ceafi.edu.br/site/wpcontent/uploads/2019/08/Obesidade-como-fator-de-risco-para-doen\%C3\%A7ascardiovasculares.pdf. Acesso em 11 abr. 2021.

RIZZATTO NUNES. Curso de direito do consumidor. 11. ed. São Paulo: Saraiva, 2017. ROSENBAUM, Paulo. Obesidade. Sociedade Beneficente Israelita Brasileira - Albert Einstein. Disponível em: https://www.einstein.br/doencas-sintomas/obesidade. Acesso em 09 abr. 2021.

SLAIBI Filho, Nagib. Direito constitucional. 3. ed. São Paulo: Grupo GEN, 2009. 